\title{
Cytotoxic Activity of Fungal Metabolites from the Pathogenic Fungus Beauveria bassiana: An Intraspecific Evaluation of Beauvericin Production
}

\author{
Jorge W. Arboleda Valencia • Alvaro L. Gaitán Bustamante • \\ Arnubio Valencia Jiménez • Ma Fátima Grossi-de-Sá
}

Received: 5 May 2011/ Accepted: 29 June 2011/Published online: 15 July 2011

(C) Springer Science+Business Media, LLC 2011

\begin{abstract}
The cyclohexadepsipeptide beauvericin (BEA) is a mycotoxin produced by the fungus Beauveria bassiana (Bals.). Using ELISA, different accessions of B. bassiana, belonging to distinct genetic groups, were analyzed to determine their variability in BEA production. The cytotoxic effect of pure mycotoxins and crude extracts was also tested on insect cell lines SF-9 and SF-21. The results showed that BEA production was significantly different between all strains. Bb 9024 exhibited the highest levels (98.56 mg/l), while $\mathrm{Bb} 9001$ the lowest $(15.66 \mathrm{mg} / \mathrm{l})$. Statistical difference was found when BEA $\mathrm{CC}_{50}$ values (2.81 and $6.94 \mu \mathrm{M}$ ) were compared with those values from others mycotoxins $(4.23-11.95 \mu \mathrm{M})$. Although no correlation has been observed between beauvericin production and phylogenetic grouping, the results suggest a comprehensible involvement of these metabolites during the infection process. The biological evaluation of metabolites produce by entomopathogenic fungi provides better criteria
\end{abstract}

J. W. A. Valencia - A. L. Gaitán Bustamante

Centro Nacional de Investigaciones de Café,

CENICAFE-FEDERACAFE, Disciplina de Fitopatologia,

Planalto Km 4 Via a Manizales, Chinchiná, Caldas, Colombia

J. W. A. Valencia

Departamento de Biologia Celular, Universidade de Brasília,

Asa Norte, Brasília, DF 70910-900, Brazil

J. W. A. Valencia (凹) · M. F. Grossi-de-Sá

Embrapa Recursos Genéticos e Biotecnologia, PqEB Final

W5 Norte, CP 02372, Asa Norte, Brasília, DF 70770-900,

Brazil

e-mail: jwarboleda@gmail.com

\section{A. V. Jiménez}

Grupo de Investigaciones Plátano, Departamento de Fitotecnia, Facultad de Ciencias Agropecuarias, Universidad de Caldas,

Calle 65 \# 26-10, Manizales, Caldas, Colombia to design more effective formulations for pest management.

\section{Introduction}

The genetic diversity of entomopathogenic populations represents an alternative in order to explore valuable microorganisms with better efficiency of insect control at field conditions [24]. A former molecular characterization of variability in $95 \mathrm{~B}$. bassiana strains indicated a low but significant degree of genetic diversity, which is not linked to geographic distribution [8]. In addition to some virulence tests, genes and metabolites of interest have been also screened to design new formulations that combine multiple mechanisms used by the fungus during the infection process. These mechanisms include the production of secondary metabolites such as the mycotoxins BEA, tenellin, bassianin, beauveriolide, oosporein and the recently described bassiacridin [18]. Mycotoxins are relatively small molecules that play an important role in fungal infection and can generate a toxic response in different organisms [22]. The ability of B. bassiana to overcome host defenses and eliminate bacterial competition has been demonstrated to be due in great part to toxin production [19].

The mycotoxin beauvericin was first discovered in $B$. bassiana [12]. It is a cyclohexadepsipeptide, consisting of three $N$-methyl phenylalanine molecules alternated with three hydroxyisovalerate acid molecules. The mycotoxin can be produced by other species of the genus Beauveria, such as Beauveria brongniartii, and by other genera [9]. Although these entomopathogens may display similar biological actions on the host insects, studies indicate that the complex profile of mycotoxin production in Beauveria 
prevents the prediction of pathogenicity and virulence [17]. Variations in mycotoxin production by entomopathogenic fungi have been previously studied [15]. A large interspecific and intraspecific variation was reported in the production of destruxin by Metarhizium anisopliae, an important toxin that gives the fungus biological efficacy as insecticide [1]. In this work, we have measured not only the variability in BEA production among the most important accessions belonging to discrete genetic groups of $\mathrm{B}$. bassiana but also the cytotoxic effect of other well-known fungal metabolites on insect cell lines.

\section{Materials and Methods}

\section{Beauveria bassiana Strains}

Beauveria bassiana $\mathrm{Bb}$ 9001, Bb 9005, Bb 9010, Bb 9011, Bb 9016, Bb 9023, Bb 9024, Bb 9119, Bb 9205; one strain of B. brongniartii ( $\mathrm{Bbr}$ 9301); and one of M. anisopliae (Ma 9236) were obtained from the microorganism collection at the National Coffee Research Center, CENICAFE, Colombia. All strains had been previously characterized using RAPDs and ITS-RFLPs molecular markets and represent the main phylogenetic groups reported by Gaitán et al. [8]. Reactivation from $0.1 \mathrm{ml}$ of stock media (10\% glycerol at $-70^{\circ} \mathrm{C}$ ) was made by plating on Petri dishes with Sabouraud dextrose agar (SDA) media supplemented with $0.4 \%$ cuticle of coffee berry borer.

\section{Preparation of Crude Extracts}

Flasks with $100 \mathrm{ml}$ of Sabouraud liquid medium at $\mathrm{pH}$ 6.8, containing $0.1 \%$ chitin, were adjusted to a concentration of $1.4 \times 10^{7}$ viable spores $/ \mathrm{ml}$ collected from dishes with all strains including Ma 9236; the flasks were incubated in an orbital shaker (150 rpm), at $27 \pm 1{ }^{\circ} \mathrm{C}, 80 \%$ relative humidity and darkness for 9 days. Liquid cultures were filtered through Whatman \#1 paper using vacuum in order to separate the crude extract from the mycelium and spore mass. Total soluble protein from liquid cultures for each strain was quantified using Branford's protocol [2] using a UNICAM UV/VIS 2 spectrophotometer at $595 \mathrm{~nm}$. Finally, filtered liquid cultures were centrifuged at $12.000 \times g$ for $30 \mathrm{~min}$, and the supernatant was then used for serological tests.

\section{ELISA Tests}

Microtiter plates were coated with $200 \mu \mathrm{l}$ of liquid supernatant from $B$. bassiana cell cultures for $24 \mathrm{~h}$ at $8^{\circ} \mathrm{C}$ and blocked in 5\% skim milk for $2 \mathrm{~h}$ and washed with TTBS (50 mM Tris- $\mathrm{HCl}, \mathrm{pH} 8.0,138 \mathrm{mM} \mathrm{NaCl}, 0.05 \%$ Tween 20) for $30 \mathrm{~min}$. The plate was incubated with a rabbit polyclonal antibody serum raised against BEA as primary antibody solution $1: 1000$ for $2 \mathrm{~h}$ at $37^{\circ} \mathrm{C}$ and washed in TTBS. A goat anti-rabbit IgG immunoglobulin $\mathrm{G}$ coupled to horseradish peroxidase (Bio-Rad) was used as the secondary antibody 1:2000 at the same conditions. Finally, a $0.01 \%(\mathrm{w} / \mathrm{v})$ solution of $3,3^{\prime}, 5,5^{\prime}$-tetramethylbenzidine in TBS containing $5 \mu \mathrm{H}_{2} \mathrm{O}_{2}$ was used as substrate. The absorbance was determined at $490 \mathrm{~nm}$. BEA concentration $(\mathrm{mg} / \mathrm{l})$ was calculated through a correlation between the sample absorbance and the curve of known concentrations constructed following the methodology above described $[\mathrm{ABS}=0.235 \quad(\mathrm{BEA}$ concentration $)+0.0268] . \quad$ Each assay was carried out with five replicates.

\section{Mycotoxin and Reagents}

The following standard fungal metabolites: oosporein (OOS), tenellin (TEN) and bassianin (BAS) with $90 \%$ of purity was a kind gift from Dr. Leo C. Vining (University of Dalhousie, Canada). BEA with $97 \%$, the reagents namely TNM-FH, heat-inactivated fetal calf serum (FCS), antibiotic solution, dimethyl sulfoxide (DMSO) and trypan blue dye solution $0.4 \%$ were purchased from Sigma (St. Louis, USA).

\section{Insect Cell Cultures and Treatments}

Lepidoptera (Spodoptera frugiperda) cell lines SF-9 and SF21 , obtained from the envelope of pupal ovaries and primary explants from pupal tissues, respectively [23], were maintained at $27^{\circ} \mathrm{C}$ in TNM-FH medium supplemented with $10 \%$ FCS and $1 \%$ penicillin-streptomycin-amphotericin solution. Cultures in the early stationary phase (typical cell density with cell viability approximately $85 \%$ ) were split every 5 days with a starting density of $2 \times 10^{5}$ cells $/ \mathrm{ml}$. The fungal metabolite standards were dissolved in methanol with the exception of BAS and TEN that were dissolved in DMSO. The standard solutions were tested at concentrations ranging from 1 to $100 \mu \mathrm{M}$. Supernatants obtained from liquid cultures of Bb 9024, Bb 9205 and Bb 9001 strains selected by BEA production were tested at concentrations ranging 1-100 ppm. Appropriate controls were prepared in the same manner without toxins (liquid media) and solvents with final concentration of $1 \%$. Afterward, the insect cells were seeded in 12-well cell culture plates at the early stationary phase $\left(1 \times 10^{6} \mathrm{cells} / \mathrm{ml}\right)$, and test solutions were added at a ratio of 1:100 (v/v). Plates were finally incubated for 48 and $72 \mathrm{~h}$ at $27^{\circ} \mathrm{C}$.

Bioassays: Cell Viability

Trypan blue dye $(0.4 \%)$ was added to insect cell cultures in a ratio of 1:1 and preparations were viewed at $100 \times$ using standard light microscopy. The ratio of live to dead cells 
(dyed) was resolved with standard curves and 50\% cytotoxic concentration $\left(\mathrm{CC}_{50}\right)$, which is the concentration of mycotoxin that caused a $50 \%$ decrease in cell viability expressed in $\mu \mathrm{M}$. Additionally, the determination of lethal concentration that caused $50 \%$ mortality values $\left(\mathrm{LC}_{50}\right)$ for the crude extracts assays was also carried out and expressed in ppm. Three independent assessments with five replicates to all bioassays were evaluated.

\section{Statistical}

The experimental unit consisted of a flask containing the corresponding strain. In all cases, five replicates per strain (treatments) were analyzed. For statistical analysis, oneway variance analysis (ANOVA) and Duncan comparison test between treatments and controls were performed. Insect cell viability statistical analyses were performed with SigmaStat 2.03 for Windows (SPSS Inc., USA), and nonparametric Tukey comparison tests were used to compare statistical differences for values obtained for $\mathrm{CC}_{50}$ and $\mathrm{LC}_{50}$ considering differences at $P \leq 0.05$ and $P \leq 0.005$, respectively. $\mathrm{LC}_{50}$ values and their lower and upper confidence limits (confidence 95\%) were calculated with the probit statistical program.

\section{Results}

\section{BEA Production Variability}

The highest concentration of BEA was observed in $\mathrm{Bb}$ 9024 and Bb 9010 with 98.60 and $98.30 \mathrm{mg} / \mathrm{l}$, respectively. On the contrary, Bb 9119 and Bb 9001 came out as the lowest producers with 18.81 and $15.66 \mathrm{mg} / \mathrm{l}$, respectively (Table 1). All strains had significant statistical differences when compared with the control (Ma 9236) and also between them, allowing the identification of three welldifferentiated groups (Table 2). Thus, the highest
Table 2 Classification by groups from levels of toxin production (Duncan test 5\%)

\begin{tabular}{llll}
\hline Duncan test & Average & N & Group \\
\hline $\mathrm{a}^{*}$ & 98.43 & 10 & I \\
$\mathrm{b}$ & 44.12 & 25 & II \\
$\mathrm{c}$ & 20.79 & 15 & III \\
\hline
\end{tabular}

$N$ total number of values by data set (Group)

* Means with the same letter are not significantly different from each group

producers of this toxin were $\mathrm{Bb} 9024$ and $\mathrm{Bb}$ 9010. The strains Bb 9011, Bb 9205, Bb 9005, Bb 9023 and $B$. brongniartii 9301 showed a medium level and $\mathrm{Bb} 9016, \mathrm{Bb}$ 9119 and $\mathrm{Bb}$ 9001, the lower expression level.

However, the $\mathrm{Bb} 9205$ strain produced the highest levels of total protein production, while the $\mathrm{Bb} 9023$ strain produced the lowest level, both belonging to the group II (middle toxin production). In addition, it was found that the strains $\mathrm{Bb} 9024$ and $\mathrm{Bb} 9010$, belonging to the first group I of toxin production showed the lowest levels of protein production when compared with the group II of toxin production (183.72 and $133.19 \mathrm{mg} / \mathrm{l}$, respectively) (Table 1). In relation to the BEA production per gram of soluble total protein, Bb 9010 strain showed the highest values while $\mathrm{Bb} 9205$ strain was located into group of the least production relating these variables, both proceeding from different genetic group. In addition, $\mathrm{Bb} 9023$ and $\mathrm{Bb}$ 9024 strains belonging to the same genetic group showed very similar levels of specific toxin production (Fig. 1).

Cytotoxic Effects of the Pure Mycotoxin on Insect Cell Viability

All B. bassiana metabolites selected for this study (BEA, OOS, BAS and TEN) showed effects on the lepidopteran cell lines SF-9 and SF-21. Metabolites that differed from BEA showed $\mathrm{CC}_{50}$ values ranging between 4.23 and
Table 1 BEA production in strains tested

Means with the same letter are not significantly different (Duncan 5\%). Data are expressed as mean \pm standard deviation

\begin{tabular}{llll}
\hline Strains & Origin & BEA production $(\mathrm{mg} / \mathrm{l})$ & Total soluble protein $(\mathrm{mg} / \mathrm{l})$ \\
\hline Bb 9001 & Colombia (Nariño) & $15.66 \pm 3.57^{\mathrm{c}}$ & $355.73 \pm 10.89^{\mathrm{e}}$ \\
Bb 9005 & Colombia (Nariño) & $37.53 \pm 13.25^{\mathrm{b}}$ & $204.54 \pm 33.85^{\mathrm{cd}}$ \\
Bb 9010 & Colombia & $98.30 \pm 8.79^{\mathrm{a}}$ & $133.19 \pm 24.61^{\mathrm{b}}$ \\
Bb 9011 & Colombia (Huila) & $69.62 \pm 20.86^{\mathrm{b}}$ & $198.76 \pm 24.86^{\mathrm{cd}}$ \\
Bb 9016 & Thailand & $27.92 \pm 4.74^{\mathrm{c}}$ & $166.21 \pm 31.21^{\mathrm{bcd}}$ \\
Bb 9023 & Philippines & $35.23 \pm 2.67^{\mathrm{b}}$ & $56.69 \pm 35.12^{\mathrm{a}}$ \\
Bb 9024 & Canada & $98.56 \pm 19.83^{\mathrm{a}}$ & $183.72 \pm 45.39^{\mathrm{cd}}$ \\
Bb 9119 & Colombia (Risaralda) & $18.81 \pm 6.39^{\mathrm{c}}$ & $156.59 \pm 28.26^{\mathrm{bc}}$ \\
Bb 9205 & Colombia & $45.79 \pm 21.29^{\mathrm{b}}$ & $475.40 \pm 67.39^{\mathrm{f}}$ \\
Bbr 9301 & Colombia (Santander) & $32.43 \pm 4.20^{\mathrm{b}}$ & $213.53 \pm 36.60^{\mathrm{d}}$ \\
Ma 9236 & Colombia & 0.00 & $201.38 \pm 23.55^{\mathrm{cd}}$ \\
\hline
\end{tabular}


Fig. 1 BEA concentration in $B$. bassiana culture extracts

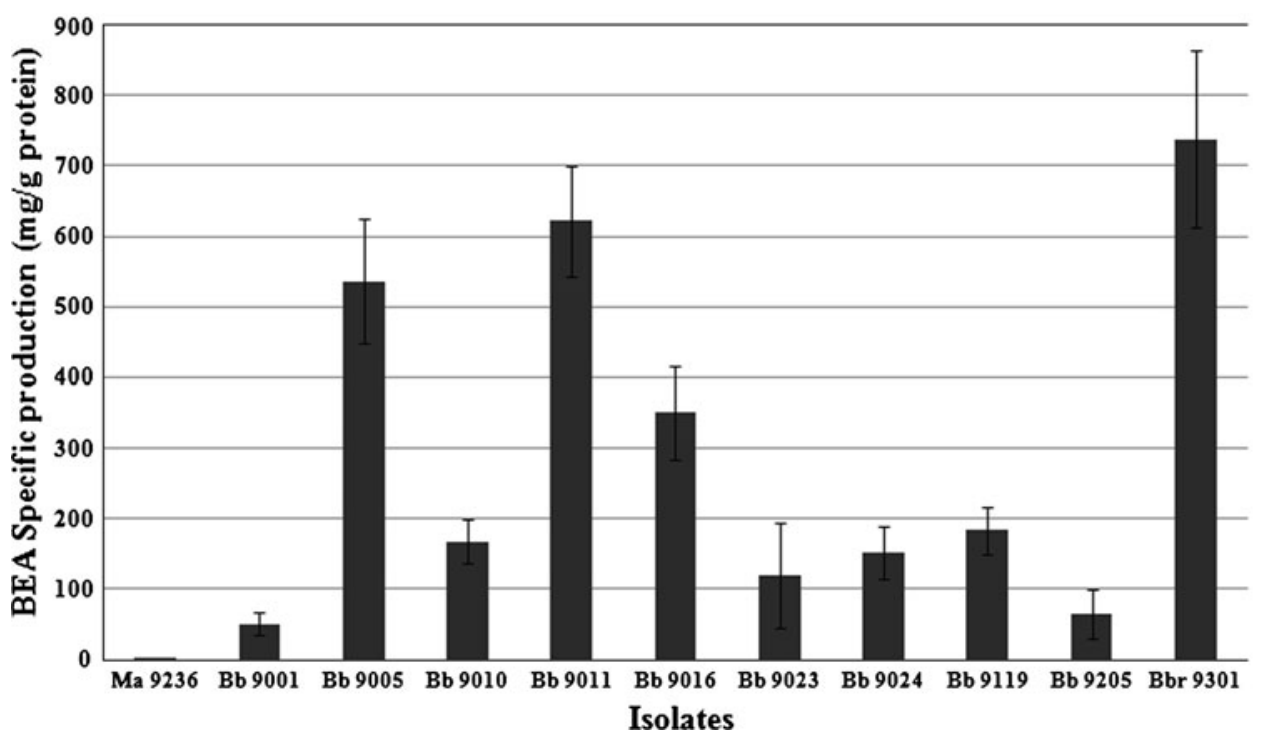

$4.84 \mu \mathrm{M}$ with SF-9 and 10.43 and $11.95 \mu \mathrm{M}$ with SF-21 (Table 3). After $48 \mathrm{~h}$ of exposure, BEA exhibited statistical differences in toxic activity on both insect cell lines in comparison with the other metabolites that were tested with $\mathrm{CC}_{50}$ of 2.81 and $6.94 \mu \mathrm{M}$ for SF-9 and SF-21, respectively. Likewise, the cell viability of both insect cell lines that was obtained from dose-response curves decreased as the toxin concentration increased, with a statistical difference at $10 \mu \mathrm{M}(P \leq 0.05 ;$ Fig. 2$)$. It is important to point out that a lower cytotoxic effect on SF-21 insect cell lines was observed in all assessments.

Effects of the Crude Extracts from Different $B$. bassiana Strains and Their Mixture on Insect Cell Viability

The $B$. bassiana strains selected for these assays belonging to different groups of BEA production were previously characterized. The results showing the effects on cell line SF-9 at 48 and $72 \mathrm{~h}$ for all crude extracts are summarized in Table 4. After $48 \mathrm{~h}$ of exposure, $\mathrm{LC}_{50}$ values for all treatments were above $100 \mathrm{ppm}$ ranging $112-316 \mathrm{ppm}$. However, after $72 \mathrm{~h}$ of exposure, all treatments increased the effect over cell line with $\mathrm{LC}_{50}$ values ranging 31-145 ppm, except $\mathrm{Bb} 9205$ with a $\mathrm{LC}_{50}$ of $451 \mathrm{ppm}$. Likewise, $\mathrm{Bb} 9024$ and $\mathrm{Bb} 9001$ showed stronger effects on cell line SF-9 with $\mathrm{LC}_{50}$ values of 31 and $37 \mathrm{ppm}$, respectively, with no statistical differences. However, statistical differences for $\mathrm{Bb} 9205$, the mixture assay and the other strains were observed at $48 \mathrm{~h}(P \leq 0.005)$. In addition, the susceptibility of cell line SF-9 to crude extract obtained from B. bassiana fungus was demonstrated. The results suggested that there was a high variation not only in BEA production but also in the content of other metabolites that facilitate the cytotoxic activity.

\section{Discussion}

Our results showed a high variation in BEA production among the different strains that were selected. Similar results were obtained by Gupta et al. [10] and Moretti et al. [15] working with B. bassiana and Fusarium spp. Furthermore, recent studies evaluating BEA and enniatins (K and I) from Fusarium species also have demonstrated a high level of diversity [21]. A survey of 24 strains in B. bassiana, made by Peczynska et al. [16], resulted in a very low frequency (12.5\%) of strains producing BEA. The present study confirms the intraspecific variability in the production of this toxic peptide (Table 1), but no correlation has been observed between beauvericin production and phylogenetic grouping. This study allowed us to determine the production of the mycotoxin, as a key aspect of variability in B. bassiana, and to evaluate its participation at the infection. BEA represents the main toxin that is produced by Beauveria spp. [10]. For this reason, the cytotoxic effect of the pure fungal metabolites (BEA, OOS, BAS and TEN) and crude extracts batches from $B$. bassiana fungus on lepidopteran cell lines SF-9 and SF-21 were tested. A direct dose-response correlation between cell viability and toxin concentration was registered when the insect cell cultures SF-9 and SF-21 were exposed to BEA. In addition, statistical difference was found between 1 and $5 \mu \mathrm{M}$ when compared with the high toxin concentration that was used $(10 \mu \mathrm{M} ; P \leq 0.05$; Fig. 2). The effect of the toxin treatment obtained with SF-9 was comparable with those obtained with A. salina [13], S. frugiperda [7] and other registered with fungal metabolites from Fusarium sp. [11].

Previous studies with BEA were carried out on murine sp. and human cellular lines showing high toxicity on the target cells [4] and on S. frugiperda cell lines [7]. To date, 
Table 3 Cytotoxicity induced by fungal metabolites on SF-9 and SF-21 insect cells, using trypan blue dye exclusion test after $48 \mathrm{~h}$

\begin{tabular}{llc}
\hline Fungal metabolites & $\mathrm{CC}_{50}(\mu \mathrm{M}) \mathrm{SF}-9$ & $\mathrm{CC}_{50}(\mu \mathrm{M}) \mathrm{SF}-21$ \\
\hline Beauvericin & $2.81 \pm 0.37^{*}$ & $6.94 \pm 0.91^{*}$ \\
Oosporein & $4.23 \pm 0.46$ & $10.43 \pm 1.14$ \\
Bassianin & $4.91 \pm 0.50$ & $12.12 \pm 1.24$ \\
Tenellin & $4.84 \pm 0.31$ & $11.95 \pm 0.76$ \\
\hline
\end{tabular}

Data are expressed as mean \pm standard deviation from three independent assessments with five replicates each

* Value differs significantly $(P \leq 0.05)$



Fig. 2 Dose-response obtained with BEA after $48 \mathrm{~h}$ of exposure; bars represent standard deviation of the mean cell viability (five replicates). To each cell line, significant differences between concentrations are indicated by different letters Tukey $(P \leq 0.05)$

Table 4 Toxicity of different crude extracts from B. bassiana and its combination on SF-9 insect cell using trypan blue dye exclusion. (LC50 values with lower and upper fiducial limits (95\%) as calculated by probit. (SPSS Inc., US)

\begin{tabular}{|c|c|c|}
\hline \multirow[t]{2}{*}{ Crude extract } & \multicolumn{2}{|l|}{$\mathrm{LC}_{50}(\mathrm{ppm})$} \\
\hline & $48 \mathrm{~h}$ incubation & $72 \mathrm{~h}$ incubation \\
\hline Bb 9205 & $264(79 ; 633)^{\mathrm{bc}}$ & $451(153 ; 1,570)^{\mathrm{c}}$ \\
\hline Bb 9024 & 190 (n.c.) $^{\text {b }}$ & $31{\text { (n.c. })^{\mathrm{a}}}$ \\
\hline Bb 9001 & $112(73 ; 233)^{\mathrm{a}}$ & $37{\text { (n.c. })^{\mathrm{a}}}$ \\
\hline $\begin{array}{l}\text { Mix (Bb } 9205 \\
\quad+9024+9001)\end{array}$ & $316{\text { (n.c. })^{\mathrm{c}}}^{\mathrm{c}}$ & $145(87 ; 384)^{\mathrm{b}}$ \\
\hline
\end{tabular}

n.c. Fiducial limits no reliable

* To each evaluation, significant differences between concentrations are indicated by different letters Tukey $(P \leq 0.005)$

this is the first report showing the effect of the pure toxins (OOS, BAS and TEN) and crude extracts produced by B. bassiana fungus on lepidopteran cell lines. Based on the results from insect cell viability assays, it was found that the $\mathrm{CC}_{50}$ value produced by those toxins was approximately two times more than the $\mathrm{CC}_{50}$ value calculated for BEA to both insect cell lines SF-9 and SF-21(Table 3). Similar $\mathrm{CC}_{50}$ values $(3.0$ and $2.5 \mu \mathrm{M})$ were reported by Fornelli et al. [7] and by Calò et al. [3] working with BEA toxin on SF-9 insect cell line. Our results also show that the cell line SF-9 is weakly more sensitive than SF-21. Furthermore, it has been demonstrated that BEA has not only antimicrobial and inhibitory effects but also insecticidal properties that generate differential insect cell susceptibility when treated with this toxin [14].

A direct relation between the toxin amount and its pathogenicity was previously reported [27], causing a progressive degeneration of the host tissues and structural changes of the membranes and also generating changes in the electrical activity of the nervous system. This modification was caused by an increased consume of oxygen as an insect attempt to get recover from the toxic effect [6]. Zizca and Wiser [28] corroborated the BEA effect on Culex pipiens larvae. They found that low toxin concentrations $(0.1 \mu \mathrm{g} / \mu \mathrm{l})$ applied topically on insects cause $44 \%$ of mortality in just $48 \mathrm{~h}$. In addition, some authors have also reported in vivo effects of fungal metabolites as agents for control of insects [25]. Some of those results show that the main symptom from insect intoxication was the generalized vacuolization and the toxic effect on the mitochondria, which swelled and took aspect of spherical vacuoles. The same effect on insect cell lines was observed in our assays under $100 \times$ light microscopy. Moreover, it was observed generalized stress and cellular lyses. However, no evidence of DNA disruption by the apoptosis process to all treatments was observed after electrophoreses (data not shown). Commonly, in this process, the nucleus chromatin is concentrated in granules localized throughout the nuclear membrane. Results obtained by Gupta et al. [9], applying BEA on Leptinotarsa decemlineata larvae, found mortalities ranging between 50 and $90 \%$ at $48 \mathrm{~h}$ at concentrations of 633 and $1,196 \mathrm{ppm}$.

In spite of the fact that the insecticidal action of the toxin has been broadly demonstrated, further research is needed to evaluate its real potential for pest control. The secondary metabolites produced by $B$. bassiana have a great potential as a natural source of different kind of substances to control pest and diseases or as new drugs [14]. Our results suggest a clear involvement of metabolites from $B$. bassiana fungus at the final infection process through its toxic activity on insect cell viability (Table 4). It is also possible that synergy and antagonism among fungal compounds could also influence the overall toxicity of the crude extracts [20]. Although the variability in BEA production has been demonstrated, strains representing each production group have been selected. No correlation 
on cell viability of the crude extract batches from $B$. bassiana and toxin production was observed. Xu et al. [26] revealed that BEA plays a highly significant but not indispensable role in virulence using knockout $B$. bassiana strain in infection assays. For example, Bb 9001 exhibited lower BEA production $(15.66 \mathrm{mg} / \mathrm{l})$ but a stronger effect on insect cell viability (SF-9) with an $\mathrm{LC}_{50}$ value of $112 \mathrm{ppm}$ at $48 \mathrm{~h}$ and $31 \mathrm{ppm}$ at $72 \mathrm{~h}$ of exposure. In a previous study, destruxin A (DTXA) from M. anisopliae showed the most toxic effect on SF-9 insect cells, with a $\mathrm{LC}_{50}$ value of $5 \mathrm{ppm}$. However, $500 \mathrm{ppm}$ of the crude extracts containing $90 \mathrm{ppm}$ of DTXA was less effective and did not cause such a high mortality [20]. Crude extract from Bb 9205 at $72 \mathrm{~h}$ and the mixture $(\mathrm{Bb} 9205+9024+9001)$ at $48 \mathrm{~h}$ resulted in less cytotoxicity $(P \leq 0.005)$ when compared with the other crude extracts that were tested. Though, treatments with Bb 9024 and Bb 9001 decreased the insect cell viability at $72 \mathrm{~h}$.

In general, the biological action of BEA is related to its ionophore property, by complexing with alkaline metals BEA creates "holes" in the cellular membrane and affects the capacity of the cell to transport and exchange substances with its environment. All these aspects must be considered in further works in order to implement and formulate biological products that involve more than one strain from a specific microorganism [5]. On the basis of our results, a complete characterization of B. bassiana for mycotoxin production and cytotoxic effect of the fungal metabolites on insect cell lines will allow to get a better selection of fungal strains, which should be more efficient for the biological control of insect pests.

\section{Conclusions}

The cytotoxic effect of BEA and pure fungal metabolites (OOS, BAS and TEN) was demonstrated. The genetic variability for the B. bassiana strains regarding BEA production was also corroborated. Our findings suggest that the cytotoxic activity of crude extracts and mycotoxin from different strains of $B$. bassiana cannot be attributed to just one toxic compound alone. Instead, the toxic effect could be the action of multiples metabolites including those mycotoxins that were tested in our experiments. The results of this study constitute a valuable aid in searching for biomolecules with high potential to be used in agriculture in order to implement appropriate solutions for pest control through biotechnological tools that allow us to prepare better formulations.

Acknowledgments The work was supported by Colombian Institute for development of Science and Technology "Francisco José de Caldas" COLCIENCIAS and National Federation of Coffee Growers of Colombia by its National Coffee Research Center, CENICAFE. We want also to thank the Coordination of Improvement of Higher Education, CAPES, Brazil, for the support given to JWAV (First Author). Additionally, the authors thank to the Laboratory of virology at CENARGEN for training given to JWAV and Universidad Católica de Manizales-UCM (Colombia) for the support received in their laboratories.

\section{References}

1. Amiri-besheli B, Khambay B, Cameron S et al (2000) Inter- and intra-specific variation in destruxin production by insect pathogenic Metarhizium spp., and its significance to pathogenesis. Mycol Res 104:447-452

2. Bradford MM (1976) A rapid and sensitive method for the quantification of microgram quantities of protein utilizing the principle of protein-dye binding. Anal Biochem 72:248-254

3. Calò L, Fornelli F, Nenna S et al (2003) Beauvericin cytotoxicity to the invertebrate cell line SF-9. J Appl Genet 44:515-520

4. Calò L, Fornelli F, Ramires R et al (2004) Cytotoxic effects of the mycotoxin beauvericin to human cell lines of myeloid origin. Pharmacol Res 49:73-77

5. Cruz LP, Gaitán A, Góngora CE (2006) Exploiting the genetic diversity of Beauveria bassiana for improving the biological control of the coffee berry borer through the use of strain mixtures. Appl Microbiol Biotechnol 71:918-926

6. Evlakhova A, Rakitin A (1968) Effect of experimental mycosis on electrical activity of nerve chain of Locusta migratoria manilensis Mey. Dokl Akad Nauk SSSR Biol Sci Sect (Engl Transl) 178:485-488

7. Fornelli F, Minervini F, Logrieco A (2004) Cytotoxicity of fungal metabolites to lepidopteran (Spodoptera frugiperda) cell line (SF9). J Invertebr Pathol 85:74-79

8. Gaitán A, Valderrama AM, Saldarriaga G et al (2002) Genetic variability of Beauveria bassiana associated with the coffee berry borer Hypothenemus hampei and other insects. Mycol Res 106: 1307-1314

9. Gupta S, Krasnoff SB, Underwood NL et al (1991) Isolation of beauvericin as an insect toxin from Fusarium semitectum and Fusarium moniliforme var. subglutinans. Mycopathologia 115: 185-189

10. Gupta S, Montlor C, Huang YS (1995) Isolation of novel beauvericin analogues from the fungus Beauveria bassiana. J Nat Prod 58:733-738

11. Gutleb A, Morrison E, Murk AJ (2002) Cytotoxicity assay for mycotoxins produced by Fusarium strains: a review. Environ Toxicol Pharm 11:309-320

12. Hamill RL, Higgens CE, Boaz HE, Gorman M (1969) The structure of beauvericin, a new depsipeptide antibiotic to Artemia salina. Tetrahedron Lett 49:4255-4258

13. Logrieco A, Moretti A, Fornelli F et al (1996) Fusaproliferin production by Fusarium subglutinans and its toxicity to Artemia salina, SF-9 insect cells, and IARC/LCL 171 Human B Lymphocytes. Appl Environ Microbiol 62:3378-3384

14. Mei L, Zhang L, Dai R (2009) An inhibition study of beauvericin on human and rat cytochrome P450 enzymes and its pharmacokinetics in rats. J Enzyme Inhib Med Chem 24:753-762

15. Moretti A, Belisario A, Tafuri A et al (2002) Production of beauvericin by different races of Fusarium oxysporum $f$. sp.melonis, the Fusarium wilt agent of muskmelon. Eur J Plant Pathol 108:661-666

16. Peczynska-czoch W, Urbánczyk MJ, Balazy S (1991) Formation of beauvericin by selected strains of Beauveria bassiana. Arch Immunol Ther Exp 39:175-179 
17. Quesada-Moraga E, Vey A (2003) Intra-specific variation in virulence and in vitro production of mycotoxins active against locust among B. bassiana (bals.) vuill. and effects of in vivo and in vitro passage on these factors. Biocontrol Sci Technol 13: 323-340

18. Quesada-Moraga E, Vey A (2004) Bassiacridin, a protein toxic for locusts secreted by the entomopathogenic fungus Beauveria bassiana. Mycol Res 108:441-452

19. Roberts DW (1981) Toxins of entomopathogenic fungi. In: Burges HD (ed) Microbial control of pests and plant disease 1970-1980. Academic Press, London, pp 441-463

20. Skrobek A, Butt TM (2005) Toxicity testing of destruxins and crude extracts from the insect-pathogenic fungus Metarhizium anisopliae. FEMS Microbiol Lett 251:23-28

21. Song HH, Lee HS, Jeong JH et al (2008) Diversity in beauvericin and enniatins H, I, and mk1688 by Fusarium oxysporum isolated from potato. Int J Food Microbiol 122:296-301

22. Turner NW, Subrahmanyam S, Piletsky SA (2009) Analytical methods for determination of mycotoxins: a review. Anal Chim Acta 632:168-180
23. Vaughn JL, Goodwin RH, Thompkins GJ et al (1977) The establishment of two cell lines from the insect $S$. frugiperda (Lepidoptera, Noctuidae). In Vitro 13:213-217

24. Vega FE, Posada F, Catherine A et al (2008) Entomopathogenic fungal endophytes. Biol Control 46:72-82

25. Vey A, Hoagland RE, Butt TM (2001) Toxic metabolites of fungal biocontrol agents. In: Butt TM, Jackson CW, Magan N (eds) Fungi as biocontrol agents. CABI Publishing, Wallingford, pp 311-346

26. Xu Y, Orozco R, Wijeratne EM et al (2008) Biosynthesis of the cyclooligomer depsipeptide Beauvericin, a virulence factor of the entomopathogenic fungus Beauveria bassiana. Chem Biol 15:898-907

27. Zacharuk R (1973) Penetration of the cuticular layers of elaterid larvae (Coleoptera) by the fungus $M$. anisopliae and notes on bacterial invasion. J Invertebr Pathol 21:101-106

28. Zizca J, Weiser J (1993) Effect of Beauvericin a toxic metabolite of Beauveria bassiana, on the ultrastructure of Culex pipiens autogenicus larvae. Cytobios 75:13-19 